\section{Dor e saúde mental}

João Augusto B. Figueiró, Gildo Angelotti e Cibele A. M. Pimenta (eds). São Paulo: Atheneu; 2005.

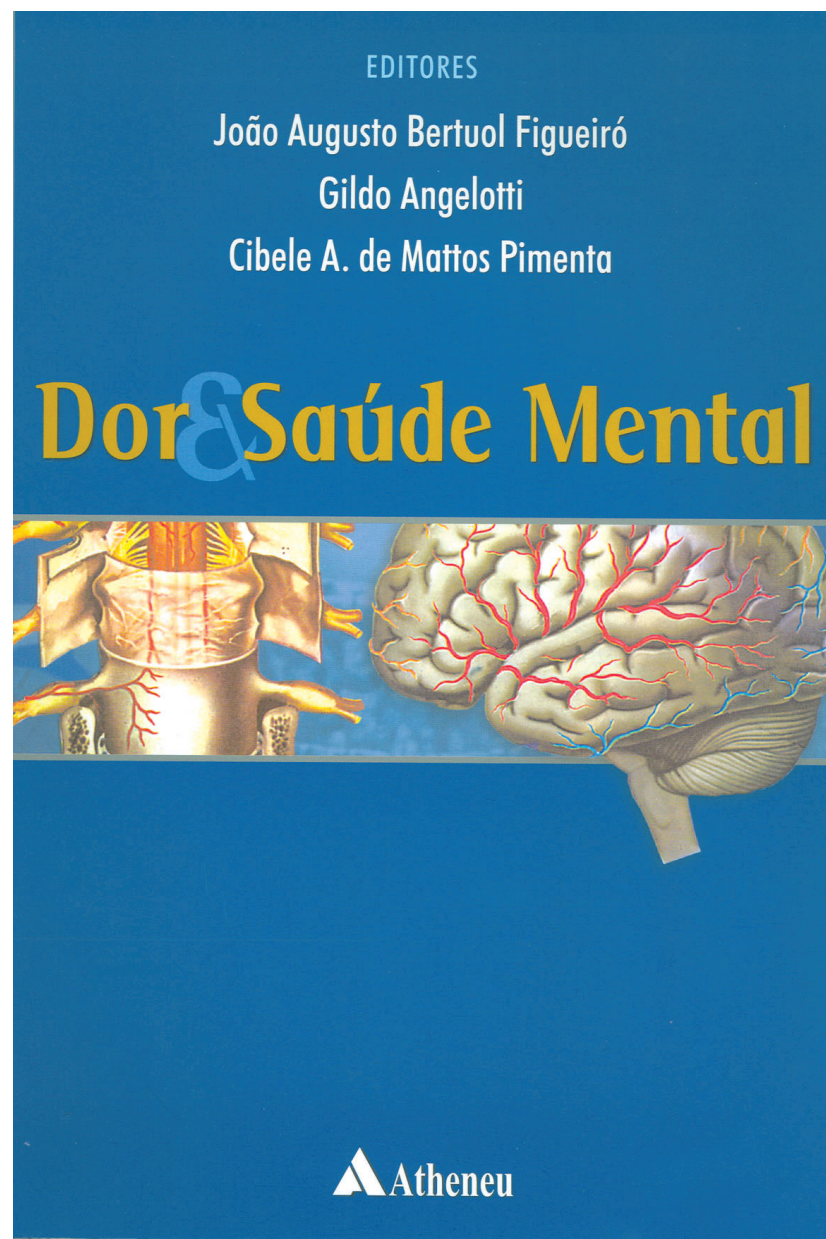

A compreensão, prevenção e tratamento da dor tem sido um desafio desde tempos imemoriais. O conceito de dor adotado pela International Association for the Study of Pain (IASP) em 1979, afirma que ela é, ao mesmo tempo, uma experiência sensorial e emocional e, além disso, um fenômeno completamente subjetivo. Enquanto as atuais pesquisas internacionais indicam consistentemente que tratamentos multidisciplinares se constituem no meio mais efetivo de tratar as síndromes dolorosas crônicas, no cotidiano de hospitais e clínicas brasileiros muito mais ênfase se dá aos aspectos orgânicos e sensoriais da dor do que aos psíquicos e socioculturais - o que, minimamente, implica em diagnósticos e tratamentos parciais.

Os editores do livro Dor e saúde mental, respectivamente um médico, um psicólogo e uma enfermeira, se propõem a lançar luz sobre a dimensão mais subjetiva do fenômeno doloroso e explorar o seu papel no sofrimento dos indivíduos. Ao longo de seus 21 capítulos, organizados em três partes, autores de diferentes especialidades procuram proporcionar infor- mações úteis que permitam aos profissionais da área da saúde conhecimentos mais amplos sobre a relação entre dor e psiquismo humano para que, com isso, possam oferecer uma assistência mais completa e integrada a seus pacientes.

A primeira parte do livro, Aspectos Gerais, fornece uma visão ampla da dor através de seus aspectos epidemiológicos, fisiopatológicos e das bases gerais de tratamento. A integração mais direta com os componentes da saúde mental se dá no capítulo sobre a fisiologia das emoções, no qual são delineadas as relações entre sensação dolorosa, medo e comportamento, e no capítulo de avaliação psicológica, que enfatiza o uso de instrumentos multidimensionais na avaliação destes indivíduos.

A segunda subdivisão do livro, Aspectos Socioculturais, parte do princípio que, tanto a percepção quanto a expressão da dor podem ser mediadas e moduladas pelos significados únicos atribuídos por cada paciente à sua condição e influenciados por seu sexo, gênero, crenças, religião e cultura. Cada um dos capítulos, embora com ênfases diferentes, irá tratar destes fatores, permitindo ao leitor uma visão mais ampla de suas inter-relações dinâmicas. Cabe destacar aqui o esforço em explorar características nacionais, como no capítulo sobre dor e cultura no qual são apresentadas algumas terapias com influência religiosa praticadas no Brasil.

Por fim, a última parte, Tratamentos Psíquicos, engloba: linhas teóricas como a Psicanálise e a Psicossomática; diferentes métodos psicoterapêuticos, como a terapia cognitivocomportamental e as terapias grupais; recursos terapêuticos como o relaxamento, a hipnose o biofeedback; os programas educativos e os psicofármacos; considerações sobre componentes envolvidos nos processos terapêuticos, tais como a depressão e os déficits de memória. Nesse sentido, esta parte do livro poderia estar mais organizada didaticamente, uma vez que, para o leitor menos familiarizado com a área, não ficam claras as indicações e as limitações nos resultados obtidos por cada uma das formas de tratamento. Mesmo assim, oferece uma visão geral dos recursos e perspectivas em saúde mental passíveis de utilização em pacientes com dor, que poderão ser empregados de acordo com os diferentes profissionais e contextos terapêuticos envolvidos.

O livro Dor e saúde mental não se propõe a esgotar o tema, conforme afirmam seus editores no prefácio, mas a apresentar os aspectos mais importantes e inspirar futuras pesquisas e publicações na área. Nesse sentido, e em seu pioneirismo, o livro é bem sucedido ao levantar no leitor a preocupação com este aspecto essencial do fenômeno doloroso e apontar novas perspectivas de compreensão e tratamento.

\section{Andréa G Portnoi}

Área de Psicologia do Grupo Multidisciplinar de Dor e Área de Psicologia da Liga de Dor, Hospital das Clínicas, Faculdade de Medicina, Universidade de São Paulo (USP), São Paulo (SP), Brasil 